\title{
Syndrome designations
}

\author{
M. MICHAEL COHEN, Jr.* \\ From Departments of Oral and Maxillofacial Surgery, Orthodontics, and Pediatrics, Schools of Dentistry \\ and Medicine, University of Washington, Seattle, USA
}

\begin{abstract}
Summary. Because syndrome designations permit the collection of data, they are much more than just labels. As new syndromes become delineated, their names connote (1) their phenotypic spectra, (2) their natural histories, and (3) their modes of inheritance or risk of recurrence. Various methods for designating new syndromes are reviewed, including naming them after (1) the basic defect, (2) an eponym, (3) one or more striking features, (4) an acronym, (5) a numeral, (6) a geographic term, and (7) some combination of the above. None of these systems of nomenclature is without fault. The advantages and disadvantages of each are discussed.
\end{abstract}

In the clinical delineation of various syndromes, a formidable vocabulary has rapidly evolved to designate them. With the exception of specialists in the field, most clinicians are baffled by the wide assortment of terms used, such as oculo-auriculovertebral dysplasia, chondrodystrophia calcificans congenita, spondyloepiphysial dysplasia of the pseudoachondroplastic type, Dubowitz syndrome, Hallermann-Streiff syndrome, Smith-Lemli-Opitz syndrome, and $B B B$ syndrome. With the discovery of new syndromes almost daily, the number of designations is expanding to the point where even specialists can no longer remember all the syndrome designations or their phenotypic features.

As in any scientific endeavour, the use of special terminology is essential for communicating ideas. However, some clinicians have maintained that labelling new syndromes is both superficial and an endeavour sui generis. Indeed, it has even been suggested that preoccupation with naming syndromes has interfered with the search for aetiology (Warkany, 1971), a view to which we do not subscribe.

Because a syndrome designation permits the collection of data, it is much more than just a label. As a syndrome becomes further delineated, its name connotes (1) its phenotypic spectrum, (2) its natural history, and (3) its mode of inheritance or

Received 22 December 1974.

* In receipt of USPHS Career Development Award. risk of recurrence. If a syndrome designation can $\vec{\varphi}$ stand for such clinically relevant information where ơ previously none existed, the designation can hardly be called 'superficial' or 'an exercise in merely applying labels'.

While the use of special terms for various syndromes is completely justified, there is no question that designations used are frequently cumbersome, unscientific, confusing, or inaccurate. The reasons for this will become apparent as we consider the various ways that have been used to designate malformation syndromes in particular.

Unquestionably, the ideal way to designate a syndrome is to use the name of the basic defect, such as an enzymatic defect or chromosomal abnormality, when this is known. The basic defect in the Sanfillippo syndrome $A$ is heparan sulphate sulphatase deficiency (McKusick, 1972; Spranger, 1976), which is also a suitable name for the disorder. Occasionally, the name of the basic defect can be unwieldy, as in hypoxanthine-guanine-phosphoribosyl-transferase deficiency. In this instance, it $N$ seems easier to use the term HGPRT deficiency or Lesch-Nyhan syndrome.

All microscopically detectable chromosomal defects associated with human malformation syndromes can be properly designated, such as trisomy 13 syndrome, 4p- syndrome, XXY syndrome, and so forth.

In the future, we can probably expect elucidation of at least some heritable disorders of connective 266 
tissue at the molecular level and hence proper designations for them. However, for a number of reasons (Grüneberg, 1947; Motulsky, 1971) the basic defect in the overwhelming majority of true multiple congenital anomaly syndromes will remain unknown. Thus, we are confronted by a bewildering variety of malformation syndromes which must be designated by some method other than naming the condition after the basic defect.

Because different systems of nomenclature have been employed, a single syndrome may be known by several terms, thus causing confusion. For example, the hypertelorism-hypospadias syndrome is also known as the Opitz syndrome (Smith, 1970) and the BBB syndrome (Opitz, Summitt, and Smith, 1969b). In general, a new syndrome may be denoted by (1) eponym, (2) one or more striking features, (3) an acronym, (4) a numeral, (5) a geographic term or (6) some combination of the above. None of these systems of nomenclature is without fault. Let us consider the advantages and disadvantages of each.

Eponyms are frequently used to designate various malformation syndromes, e.g. Seckel syndrome, Russell-Silver syndrome, and Klippel-TrénaunayWeber syndrome. McKusick (1971) has argued against using the possessive form of an eponym since others have often contributed to our understanding of a given syndrome. Thus, Apert's syndrome is incorrect, since the disorder was described earlier by some (see Apert, 1906) and has become more fully understood subsequently because of the work of others (Park and Powers, 1920; Blank, 1960; Schauerte and St.-Aubin, 1966). Furthermore, to paraphrase Warkany (1971), Apert neither had nor owned the syndrome he described. Thus, the term Apert syndrome or the Apert syndrome seems preferable.

Two or more names are found in some eponyms and may indicate various things. The SmithLemli-Opitz syndrome indicates collaboration. The Morquio-Brailsford syndrome indicates independent simultaneous discovery. The PeutzJeghers syndrome indicates revival by Jeghers of Peutz's earlier observations. Some eponyms honour clinicians who have added new facets to an already established syndrome, e.g. Sturge-WeberKrabbe syndrome. In some instances, an eponym seems briefer than the accepted scientific term. For example, it seems easier to say Osler-RenduWeber syndrome than hereditary haemorrhagic telangiectasia. Finally, some eponyms are used because an alternative term has become aetiologically heterogeneous since it was first described. For example, the Conradi syndrome used to be synonymous with chondrodystrophia calcificans congenita (now changed to chondrodysplasia punctata). Since there are now at least two aetiologically distinct forms of chondrodysplasia punctata (Spranger, Opitz, and Bidder, 1971) the term Conradi syndrome is restricted to the autosomal dominant form.

There are several advantages in using eponyms. Since eponyms avoid anatomical description, expansion of the syndrome can take place as new facets are recognized without changing the name of the syndrome. Furthermore, eponyms do not bias the phenotypic spectrum of future reports because there are no features of the syndrome in the designation. Nor do eponyms suggest a false aetiology, prejudge the search for the basic defect, or conceal our ignorance of the nature of the disorder. The Hurler syndrome used to be known as lipochondrodystrophy, erroneously suggesting a basic defect in fat metabolism (McKusick, 1972). Obviously, the Hurler syndrome was a better suited name. Furthermore, when the basic defect became known ( $\alpha$-L-iduronidase deficiency), this designation could be substituted for the interim term Hurler syndrome.

One major disadvantage of eponyms is that more than one syndrome may be named after the same individual. This is especially true in the study of malformation syndromes where a single clinician often discovers more than one syndrome. For example, Opitz's name appears in three different designations, i.e. Optiz syndrome (hypertelorismhypospadias syndrome) (Smith, 1970), LeroyOpitz syndrome (mucolipidosis 11) (Hansen, 1972), and Smith-Lemli-Opitz syndrome. Thus, confusion confronts the neophyte who attempts to master nosology in the field irrespective of what device is used to separate various syndromes whose designations include the same name.

Another disadvantage briefly alluded to earlier is that frequently the individual for whom the syndrome was named was not the first to describe it. For example, the Down syndrome was reported earlier by Seguin (Warkany, 1971). In some instances, it is argued that credit should not necessarily be given to the first author who described a syndrome, but to the author who recognized the syndrome as an entity or in some way illuminated the disorder. For example, though the de Lange syndrome was reported earlier by Brachmann (Opitz et al, 1965) Berg et al (1970) have suggested retention of the designated de Lange syndrome rather than Brachmann-de Lange syndrome because of the illuminating quality of de Lange's contribution. In other instances, it is 
argued that any author who contributes to our understanding of a given syndrome should be included in the eponym. This reaches ridiculous extremes in the Luschka-Schirmer-Sturge- Kalischer - Hebold - Dimitri - Brushfield - Wyatt Weber-Krabbe syndrome, as pointed out by Warkany (1974).

That whim enters into the assignment and persistence-or lack of persistence-of an eponym is evident. We retain the term Marfan syndrome, though Marfan's original patient had congenital contractual arachnodactyly and not the Marfan syndrome (Hecht and Beals, 1972). The PraderWilli syndrome was originally described by Prader, Labhart, and Willi (1956). However, Labhart's name has mysteriously vanished from the designation.

Syndromes have been designated by one or more of their features. In some cases a single striking feature provides a name by which the syndrome can be remembered with ease, as in the whistling face syndrome. Sometimes anatomical designations include two or more features of a syndrome, as in the hypertelorism-hypospadias syndrome or trichorhino-phalangeal syndrome. Because such terms are descriptive, they can aid the clinician in remembering some of the presumably common features of a given syndrome.

There are several disadvantages in using syndrome features as designations. First, the name may be too general as in the term cerebro-hepatorenal syndrome for the Zellweger syndrome. Since cerebro-hepato-renal is non-specific, the designation could apply equally well to the Wilson disease (McKusick, 1969). Second, some designations are simply incorrect. Adenoma sebaceum syndrome is an inaccurate term for tuberous sclerosis because angiofibromas and not sebaceous adenomas are features of the disorder. Third, introducing anatomical terminology into the designation biases the phenotypic spectrum of future reports. In fact, anatomical features honoured in the designation tend to become obligatory rather than facultative, resulting in the danger that some clinicians will not diagnose a syndrome unless such features are present. Patients with the macroglossia-omphalocele (Beckwith-Wiedemann) syndrome may lack both macroglossia and omphalocele. Cases without either feature have been documented in which the visceral histological lesions of the syndrome were florid (Cohen et al, 1971).

Fourth, anatomical designations do not allow for further syndrome delineation within the name itself. For example, if we report a new syndrome which we designate as the auriculo-digito-renal syndrome and, with further delineation, it becomes apparent that ocular and cardiac defects are also striking features of the syndrome, in fact more common than either the digital or renal anomalies, then the original designation no longer fits the syndrome. To change the already established name to auriculo-oculo-cardio-digito-renal syndrome is confusing as well as frightfully unwieldy.

Fifth, some designations are too complex to begin with such as occipito-facial-cervico-thoracic-abdomino-digital dysplasia (Peréz-Comas and GarciáCastro, 1974). Finally, some designations may have unpleasant connotations for the affected individual or his family or both. Terms such as bird-headed dwarfism, gargoylism, and many others should be disregarded for this reason.

Acronyms have been used to designate some malformation syndromes. They may serve as useful mnemonic devices, as in the LEOPARD syndrome (multiple lentigines, electrocardiographic conduction abnormalities, ocular hypertelorism, pulmonary stenosis, atrial septal defect, retardation of growth, and sensorineural deafness (Gorlin and Cohen, 1976). Acronyms based on the initials of the original patient's surnames have also been proposed, e.g. G, SC, and RSH syndromes (Opitz et al, 1969a, c; Herrmann et al, 1969). Such designations have not been favourably received, in part because they are difficult to remember. However, it should be noted that such designations (1) readily lend themselves to computer diagnosis and information retrieval systems and (2) do not bias the phenotypic spectrum of future reports. Other syndrome designations have been abbreviated by using various combinations of letters, e.g. EvC (Ellis-van Creveld syndrome) (McKusick et al, 1964), and EMG (exomphalos-macroglossia-gigantism or Beckwith-Wiedemann syndrome) (Irving 1970).

Designation with numerals have been used (1) to subclassify various syndromes when knowledge expands, as in the mucopolysaccharidoses (MPS I-VII) (McKusick, 1972; Spranger, 1976); (2) to separate quite different disorders with the same eponym, as in the Hanhart syndromes (types 1 to IV) (Leiber and Olbrich, 1966); and (3) to separate quite different disorders with the same descriptive label, as in achondrogenesis (types I and II) (Freire-Maia and Lenz, 1969). Generally speaking, numerical nomenclature has found its most important use in those areas where knowledge at the biochemical level has rapidly shown aetiological heterogeneity, as in the mucopolysaccharidoses. Numerals are easy to use, allow for the discovery of 
additional subtypes, and have no built-in phenotypic biases in their designations.

Two major disadvantages are inherent in this approach. First, it is difficult to remember syndrome designations with numerals and it becomes even more difficult as the number of such designations increases. A second disadvantage is that numerical changes other than additions are likely to occur as our understanding of various syndromes is enhanced, thus causing confusion. For example, in 1966 the mucopolysaccharidoses were simply classified as MPS I-VI. By 1972, MPS I as a simple designation no longer existed. In its place were MPS $1 \mathrm{H}$ (Hurler syndrome), MPS I S (Scheie syndrome), and MPS I H/S (Hurler-Scheie compound). Furthermore, MPS V, which used to be the designation for the Scheie syndrome became vacant (McKusick, 1972; Spranger, 1976).

The least common way to designate various syndromes is by geographical location of the original patients. Thus, the term Brazilian type achondrogenesis was introduced because most cases had been ascertained in central Brazil (Freire-Maia and Lenz, 1969). In general, geographical designations have not been favourably received by students of malformation syndromes.

Finally, compound designations of various types may be used. In many instances such terms can help clarify which syndrome is under discussion. For example, the Hurler syndrome may be designated as $\alpha$-L-iduronidase deficiency (Hurler syndrome) or as Hurler syndrome (MPS I H). Subtyping descriptive terms with eponyms has been used in the International Nomenclature for Constitutional Diseases of Bone (1970, 1971). For example, metaphyseal chondrodysplasia is subclassified as Jansen, Schmid, or McKusick type. Similar compound designations have been advocated by Smith (1974), e.g. Taybi oto-palato-digital syndrome.

In the second edition of Syndromes of the Head and Neck (Gorlin and Cohen, 1976), we used an eclectic approach to nomenclature. We chose a primary designation for each syndrome on the basis of how it was most commonly known. We also chose a second designation on the basis of the next most commonly used term. Designations were selected without regard for consistency of nomenclature, thus following Emerson who stated that 'consistency is the hobgoblin of little minds'.

\section{REFERENCES}

Apert, E. (1906). De l'acrocéphalosyndactylie. Bulletin de la Société de Médecine (Paris), 23, 1310-1330.

Berg, J. M., McCreary, B. D., Ridler, M. A. C., and Smith, G. F. (1970). The de Lange Syndrome. Pergamon Press, Oxford.
Blank, C. E. (1960). Apert's syndrome (A type of acrocephalosyndactyly): observations on a British series of thirty-nine cases. Annals of Human Genetics, 24, 151-165.

Cohen, M. M., Jr., Gorlin, R. J., Feingold, M., and tenBensel, R. W. (1971). The Beckwith-Wiedemann syndrome. American fournal of Diseases of Children, 122, 515-519.

Freire-Maia, N. and Lenz, W. D. (1969). Discussion. Birth Defects, 5 (4), 14-16.

Gorlin, R. J. and Cohen, M. M., Jr. (1976). Syndromes of the Head and Neck, 2nd ed. McGraw-Hill, New York.

Grüneberg, H. (1947). Animal Genetics and Medicine, P. B. Hoeber, New York.

Hansen, H. G. (1972). Haematologic studies in mucopolysaccharidoses, and mucolipidoses. Birth Defects, 8 (3), 115-128.

Hecht, F. and Beals, R. K. (1972). 'New' syndrome of congenital contractural arachnodactyly originally described by Marfan in 1896. Pediatrics, 49, 574-579.

Herrmann, J., Feingold, M., Tulfi, G. A., and Opitz, J. M. (1969). A familial dysmorphogenetic syndrome of limb deformities, characteristic facial appearance and associated anomalies: the 'pseudothalidomide' or 'SC-syndrome'. Birth Defects, 5 (3), 81-89.

Irving, I. (1970). The E.M.G. syndrome (exomphalos, macroglossia, gigantism). In Progress in Pediatrics, pp. 1-61. Ed. by P. P. Rickham, W. C. Hacker, and J. Prevot. Urban and Schwartzenberg, Munich.

Lieber, B. and Olbrich, G. (1966). Die Klinischen Syndrome, 4th ed. Urban and Schwarzenberg, Munich and Berlin.

McKusick, V. A. (1969). Editor's comment on terminology. Birth Defects, 5 (2), 158.

McKusick, V. A. (1971). Mendelian Inheritance in Man, 3rd ed. Johns Hopkins Press, Baltimore.

McKusick, V. A. (1972). Heritable Disorders of Connective Tissue, 4th ed. C. V. Mosby, St. Louis.

McKusick, V. A., Eldrige, R., Hostetler, J. A., and Egeland, J. A. (1964). Dwarfism in the Amish. Transactions of the Association of American Physicians, 77, 151-168.

Motulsky, A. G. (1971). Biochemical genetics of hemoglobins and enzymes as a model for birth defects research. In Congenital Malformations, pp. 199-208. Excerpta Medica, Amsterdam.

Nomenclature for Constitutional Diseases of Bone (1970, 1971). Annales de Radiologie, 13, 455-464; Fournal of Pediatrics, 78, 177-179.

Opitz, J. M., Friás, J. L., Gutenberger, J. E., and Pellett, J. R. (1969a). The $G$ syndrome of multiple congenital anomalies. Birth Defects, 5 (2), 95-101.

Opitz, J. M., Segal, A. T., Lehrke, R. L., and Nadler, H. L. (1965) The etiology of the Brachmann-deLange syndrome. Birth Defects Reprint Series, 22-33.

Opitz, J. M., Summitt, R. L., and Smith, D. W. (1969b). The BBB syndrome-familial telecanthus with associated congenital anomalies. Birth Defects, 5 (2), 86-94.

Opitz, J. M., Zellweger, H., Shannon, W. R., and Ptacek, L. J. (1969c). The RSH syndrome. Birth Defects, 5 (2), 43-52.

Park, E. A. and Powers, G. F. (1920). Acrocephaly and scaphocephaly with symmetrically distributed malformations of the extremities. American fournal of Diseases of Children, 20, 235-315.

Peréz-Comas, A. and Garciá-Castro, J. M. (1974). Occipitofacial-cervico-thoracic-abdomino-digital dysplasia; Jarcho-Levin syndrome of vertebral anomalies. Fournal of Pediatrics, 85, 388391.

Prader, A., Labhart, A., and Willi, H. (1956). Ein Syndrom von Adipositas, Kleinwuchs, Kryptorchismus and Oligophrenie nach myatonieartigem Zustand im Neugeborenenalter. Schweizerische medizinische Wochenschrift, 86, 1260.

Schauerte, E. W. and St.-Aubin, P. M. (1966). Progressive synosteosis in Apert's syndrome (acrocephalosyndactyly). American fournal of Roentgenology, 91, 67-73.

Smith, D. W. (1970). Recognizable Patterns of Human Malformation. W. B. Saunders, Philadelphia. 
Smith, D. W. (1974). Nomenclature of syndromes. Birth Defects, 10 (7), 65-67.

Spranger, J. W. (1976). The mucopolysaccharidoses. In Syndromes of the Head and Neck, 2nd ed. Ed. by R. J. Gorlin and M. M. Cohen, Jr. McGraw-Hill, New York.

Spranger, J. W., Opitz, J. M., and Bidder, U. (1971). Hetero-

geneity of chondrodysplasia punctata. Humangenetik, 11, 190- (D) 212.

Warkany, J. (1971). Syndromes. American fournal of Diseases of Children, 121, 365-370; Congenital Malformations. Notes and Comments, pp. 43-48. Year Book Medical Publishers, Chicago. Warkany, J. (1974). Overview of malformation syndromes. Birth Defects, 10 (7), 1-5. 